\title{
Demonstration of the intracellular production of tissue-destructive protease by Legionella pneumophila multiplying within guinea-pig and human alveolar macrophages
}

\author{
Catherine Rechnitzer, ${ }^{1 *}$ AnN Williams, ${ }^{2}$ J. Barry Wright, ${ }^{1}$ A. Barry Dowsett ${ }^{2}$ \\ Nils MILMAN ${ }^{3}$ and RoY B. FitzGEORGE ${ }^{2}$ \\ ${ }^{1}$ Department of Clinical Microbiology, 7806, Rigshospitalet, Tagensvej 20, DK-2200, Copenhagen, Denmark \\ ${ }^{2}$ Division of Pathology, PHLS Centre for Applied Microbiology and Research, Porton Down, Salisbury, UK \\ ${ }^{3}$ Department of Pulmonary Medicine, Copenhagen County Hospital at Gentofte, Denmark
}

(Received 12 November 1991; revised 6 February 1992; accepted 1 May 1992)

\begin{abstract}
The major extracellular enzyme of Legionella pneumophila, a metalloprotease, has been proposed as a pathogenic factor in Legionnaires' disease due to its cytotoxic, tissue-destructive, and phagocyte-inhibitory properties. The relevance of these activities depends on the production of the protease during infection, i.e. by $L$. pneumophila multiplying intracellularly. In this study, $L$. pneumophila was demonstrated to produce protease in guinea-pig and human alveolar macrophages infected in vitro. After $24 \mathrm{~h}$ infection, approximately $0 \cdot 1$ to $0 \cdot 2 \mu \mathrm{g}$ of protease per $10^{6}$ bacteria was measured by ELISA in culture supernatants and lysates of the infected cells, whereas no protease could be detected immediately after infection. Immunogold labelling using anti-protease antibody showed the enzyme to be located within phagosomes and distributed throughout the macrophages. Recent observations have shown that this protease could modify host defence mechanisms through inhibition of bacterial killing by neutrophils and monocytes. The intracellular production of the enzyme in infected macrophages demonstrated here further supports a role for the protease in the pathogenesis of Legionnaires' disease.
\end{abstract}

\section{Introduction}

Legionella pneumophila, a facultatively intracellular Gram-negative bacterium, appears to be the most common cause of Legionnaires' disease. This bacterium is able to multiply intracellularly within a variety of cells, e.g. human monocytes (Horwitz \& Silverstein, 1980), monocyte-derived macrophages (Rajagopalan et al., 1987) and alveolar macrophages (Nash et al., 1984; Mintz et al., 1988), as well as alveolar and peritoneal macrophages of guinea-pigs (Elliott \& Winn, 1986; Kishimoto et al., 1981; Yamamoto et al., 1987; Yoshida et al., 1987). The dominant extracellular enzyme produced by $L$. pneumophila is a zinc metalloprotease also called tissue-destructive protease, cytolysin or major secretory protein (Conlan et al., 1986; Dreyfus \& Iglewski, 1986; Belyi et al., 1988; Blander \& Horwitz, 1989). This protease is toxic to different types of cells and causes tissue destruction and pulmonary damage (Baskerville et al., 1986; Conlan et al., 1986; Rechnitzer et al.,

* Author for correspondence. Tel. 45 35457736; fax 4531398331. Abbreviation: FCS, foetal calf serum. 1989a; Rosenfeld et al., 1986), which suggests its involvement in the pathogenesis of Legionnaires' disease. In further support of a role for protease as a pathogenic factor, we have recently described the inhibitory effect of the enzyme on the function of human neutrophils and monocytes, affecting particularly the microbicidal activity of these cells (Rechnitzer \& Kharazmi, 1992). The relevance of these in vitro observations largely depends on the presence of the protease at the site of infection where the phagocytes are concentrated. In vivo production of the protease has been demonstrated by Conlan et al. (1988) in whole-lung macerates taken from guinea-pigs with experimental Legionnaires' disease. Whilst immunocytochemical studies have shown the presence of protease within guineapig alveolar macrophages in vivo (Williams et al., 1987), production of the enzyme by $L$. pneumophila multiplying intracellularly has not been demonstrated. The present study was designed to investigate, by ELISA, the intracellular production of protease in guinea-pig and human alveolar macrophages infected in vitro with $L$. pneumophila. 


\section{Methods}

Organism. L. pneumophila, Corby strain, is a serogroup 1 human isolate (kindly provided by $\operatorname{Dr}$ R. A. Swann, John Radcliffe Hospital, Oxford, UK). Stock cultures, stored at $-70^{\circ} \mathrm{C}$, were thawed and grown on buffered charcoal yeast extract agar plates supplemented with 2-oxoglutarate (BCYE). Bacterial suspension was adjusted spectrophotometrically to $10^{8}$ bacteria $\mathrm{ml}^{-1}$.

Guinea-pig alveolar macrophages. Lungs taken post mortem from normal guinea-pigs were washed out in Eagle's minimal essential medium (MEM) containing $10 \mathrm{mM}$-sodium bicarbonate, $20 \mathrm{~mm}$ HEPES, $20 \mathrm{~mm}$-L-glutamine and $5 \mathrm{U}^{2}$ heparin $\mathrm{ml}^{-1}$ (MEMa) using a procedure described by Jepras et al. (1985). Cells were harvested from the lavage by centrifugation at $200 \mathrm{~g}$ for $10 \mathrm{~min}$ and resuspended in MEM containing $5 \%(\mathrm{v} / \mathrm{v})$ autologous guinea-pig serum (MEMb). Cells were counted in a Neubauer haemocytometer chamber, adjusted to $10^{\circ}$ macrophages $\mathrm{ml}^{-1}$ and $200 \mu \mathrm{l}$ aliquots added to wells of a 96well tissue culture plate (Nunc). Cells were allowed to settle at $37^{\circ} \mathrm{C}$ for $30 \mathrm{~min}$. Non-adherent cells were then washed away with MEMb.

Human alveolar macrophages. Bronchoalveolar lavage (BAL) was performed under local anaesthesia in uninfected patients undergoing diagnostic bronchoscopy. Informed consent had been obtained prior to bronchoscopy. A flexible fibreoptic bronchoscope was wedged in a middle or lower lobe bronchus of the normal lung and $200 \mathrm{ml}$ of prewarmed sterile saline instilled in aliquots of $50 \mathrm{ml}$. After each instillation, the BAL fluid was aspirated and collected in polyethylene tubes. On average, $70 \%$ of the instillated fluid was recovered. BAL fluids used in the study were found free of tumour cells and microbiological examination was performed to exclude infected samples. The cells were harvested by centrifugation and washed twice with RPMI 1640 medium containing $25 \mathrm{mM}$-HEPES and $2 \mathrm{mM}$-Lglutamine, $\mathrm{pH} 7.4$ (hereafter called RPMI). Total and differential cell counts were done using methyl violet and nonspecific esterase staining, respectively. Macrophages represented $90-95 \%$ of the total cell population. Cell suspensions were adjusted to $5 \times 10^{5} \mathrm{ml}^{-1}$ in RPMI containing $20 \%$ foetal calf serum (FCS; Bodinco), penicillin $\left(500 \mu \mathrm{g} \mathrm{ml}^{-1}\right)$ and streptomycin $\left(50 \mu \mathrm{g} \mathrm{ml}^{-1}\right)$. One millilitre of cell suspension was layered onto each well of a 24-well multidish (Nunc) and left for adherence for $90 \mathrm{~min}$ at $37^{\circ} \mathrm{C}$ in $5 \%(\mathrm{v} / \mathrm{v}) \mathrm{CO}_{2}$. The nonadherent cells were then removed by gentle washing twice with RPMI. The monolayers were further incubated for $24 \mathrm{~h}$ in medium containing $20 \%(\mathrm{v} / \mathrm{v}) \mathrm{FCS}$ and antibiotics, then washed twice and incubated for $48 \mathrm{~h}$ without antibiotics.

Infection of guinea-pig alveolar macrophages. Bacterial suspensions were quantified by viable count on BCYE, suspended in MEMb and added to macrophages at a concentration which yielded 100 organisms per macrophage. A $2 \mathrm{~h}$ period of incubation was allowed for ingestion of organisms, then extracellular bacteria were killed by incubating for $2 \mathrm{~h}$ with $50 \mu \mathrm{g}$ gentamicin $\mathrm{ml}^{-1}$ in MEMb followed by three washes with $\mathrm{MEMb}$, a procedure which does not kill intracellular $L$. pneumophila (Fitzgeorge, 1985). To count intracellular bacteria the macrophages were disrupted using $200 \mu 10.8 \%$ (w/v) digitonin in sterile distilled water per well for $10 \mathrm{~min}$ at $37^{\circ} \mathrm{C}$. This detergent does not affect the viability of $L$. pneumophila (Fitzgeorge, 1985). The contents of each well were aspirated and added to $1.8 \mathrm{ml}$ distilled water. This suspension, diluted further as necessary, was plated onto BCYE agar plates. Extracellular organisms were enumerated by plating out serial dilutions of culture supernatants. Intracellular growth of organisms was investigated by incubating infected macrophages at $37^{\circ} \mathrm{C}$ for $24 \mathrm{~h}$ followed by digitonin treatment and enumeration. Colonies were counted after $3 \mathrm{~d}$ incubation at $37^{\circ} \mathrm{C}$ in all cases. Protease in the culture supernatants and the cell lysates was assayed by ELISA. Controls were included to determine the effects of digitonin, MEMb, and supernatants and lysates of non-infected macrophages on the assay and growth of bacteria in MEMb. During the course of infection macrophages were examined by phase-contrast microscopy.

Infection of human alveolar macrophages. Infection of the monolayers was performed as described by Rajagopalan et al. (1987). The monolayers were washed twice with RPMI, and bacterial suspension in RPMI with $20 \%(\mathrm{v} / \mathrm{v})$ pooled normal human serum was added to each well at a ratio of 10 organisms per macrophage. The multidishes were then incubated for $60 \mathrm{~min}$, rotating at 150 r.p.m., in $5 \%(\mathrm{v} / \mathrm{v}) \mathrm{CO}_{2}$ at $37^{\circ} \mathrm{C}$. Following infection, the cells were washed 10 times in order to remove any extracellular bacteria. Supernatants from triplicate wells were harvested and adherent cells lysed with $0.5 \mathrm{ml}$ cold sterile distilled water per well. Serial dilutions of supernatants and lysates were plated onto BCYE plates and c.f.u. enumerated after $72-96 \mathrm{~h}$ incubation at $37^{\circ} \mathrm{C}$. The multidishes were further incubated for $24 \mathrm{~h}$ at $37^{\circ} \mathrm{C}$ in $5 \%$ (v/v) $\mathrm{CO}_{2}$. Triplicate supernatants and lysates were harvested as above. Supernatants and lysates of non-infected cells identically treated were harvested to be used as control in the ELISA. Control cultures consisted of $0.5 \mathrm{ml}$ bacterial suspension in RPMI-FCS placed in triplicate wells containing no cells. Macrophages were examined by phase-contrast microscopy as above.

ELISA for protease. The protease and anti-protease antibody used in this study have been used and validated previously by Conlan et al. (1986, 1988). Briefly, protease was purified from broth culture supernatants by gel filtration followed by ion-exchange chromatography. Purity was verified on Coomassie-blue and silver-stained SDSPAGE gels. Anti-protease antibody was prepared by immunization of New Zealand White rabbits with the purified protease. The IgG fraction was obtained from high-titre antisera by protein A affinity chromatography and anti-protease $\mathrm{IgG}$ further purified by affinity chromatography on a protease-Sepharose column. The specificity of this antibody has been demonstrated by Western blots (Conlan et al., 1988).

Supernatants and lysates were titrated by a sandwich ELISA as described by Conlan et al. (1988) with minor modifications. Briefly, 96well immunoplates (MaxiSorb, Nunc) and $100 \mu \mathrm{l}$ volumes of the different reagents were used at room temperature. PBS containing $0.1 \%$ Tween 20 was used as wash solution and wash solution with $10 \%$ (v/v) FCS as diluent. Coating was performed overnight with antiprotease $\mathrm{IgG}$ at $4 \mu \mathrm{g} \mathrm{ml}^{-1}$. Horseradish-peroxidase-conjugated antiprotease IgG was used at $4 \mu \mathrm{g} \mathrm{ml}^{-1}$. The substrate used was $3,3^{\prime}, 5,5^{\prime}$ tetramethylbenzidine dissolved in DMSO and diluted to $0.1 \mathrm{mg} \mathrm{ml}^{-1}$ in $50 \mathrm{~mm}$-sodium acetate/acetic acid buffer, $\mathrm{pH} 6 \cdot 0$, with $\mathrm{H}_{2} \mathrm{O}_{2}$ added to $0.007 \%$. The reaction was stopped by addition of $25 \mu \mathrm{l} 1 \mathrm{M}-\mathrm{H}_{2} \mathrm{SO}_{4}$ and absorbance was read using an automatic ELISA reader (Bio-Rad) with a $450 \mathrm{~nm}$ filter. A twofold dilution row of purified tissue-destructive protease (at $5.5 \mu \mathrm{g} \mathrm{ml}^{-1}$ ) was included on each plate to generate a standard curve from which the apparent concentration of protease in each sample was derived.

Immunocytochemistry. Immunolabelling of organisms and protease in guinea-pig macrophages by electron microscopy was performed as previously described (Williams et al., 1987). Briefly, macrophages were incubated with bacteria for $2 \mathrm{~h}$ in siliconized glass tubes and following removal of extracellular organisms, were incubated for $24 \mathrm{~h}$ at $37^{\circ} \mathrm{C}$. Cells were pelleted, then resuspended and fixed in $1 \mathrm{ml} 0.1 \%$ glutaraldehyde in phosphate buffer for $1 \mathrm{~h}$ at $4{ }^{\circ} \mathrm{C}$, then pelleted in agar. The pellet was cut into 1-2 mm cubes and processed to Araldite as described by Williams et al. (1987). Sections $80 \mathrm{~nm}$ thick were immunogold labelled using an indirect method with the affinitypurified rabbit anti-protease described above, followed by goat antirabbit IgG gold (10 nM; Seralab). Controls using rabbit IgG in place of specific antibody were included. 
Table 1. Production of tissue-destructive protease by L. pneumophila multiplying within guineapig alveolar macrophages

Results of four independent experiments are presented. Viable counts and protease concentration were determined in duplicate. ND, Not detected (the limit of detection of the ELISA was $5 \mathrm{ng}$ of protease); NT, not tested.

\begin{tabular}{|c|c|c|c|c|c|}
\hline \multirow[b]{2}{*}{$\begin{array}{l}\text { Time } \\
\text { (h) }\end{array}$} & \multirow[b]{2}{*}{ Expt } & \multicolumn{2}{|c|}{ Supernatant } & \multicolumn{2}{|c|}{ Lysate } \\
\hline & & $\begin{array}{l}\text { Viable count } \\
\text { (c.f.u. } \mathrm{ml}^{-1} \text { ) }\end{array}$ & $\begin{array}{l}\text { Concn of protease } \\
\left(\mu \mathrm{g} \text { per } 10^{6} \text { bacteria) }\right.\end{array}$ & $\begin{array}{l}\text { Viable count } \\
\text { (c.f.u. } \mathrm{ml}^{-1} \text { ) }\end{array}$ & $\begin{array}{l}\text { Concn of protease } \\
\text { (ug per } 10^{6} \text { bacteria) }\end{array}$ \\
\hline \multirow[t]{4}{*}{0} & 1 & 0 & ND & $2.4-2.5 \times 10^{3}$ & ND \\
\hline & 2 & NT & NT & $2.4-2.7 \times 10^{5}$ & ND \\
\hline & 3 & NT & NT & $2.2-3.6 \times 10^{5}$ & ND \\
\hline & 4 & NT & NT & $4 \cdot 1-7 \cdot 1 \times 10^{3}$ & ND \\
\hline \multirow[t]{4}{*}{24} & 1 & NT & NT & NT & NT \\
\hline & 2 & $8 \cdot 3-9 \cdot 1 \times 10^{6}$ & $0.074(0.071-0.078)$ & $5.0-6.9 \times 10^{6}$ & $0.221(0.210-0.232)$ \\
\hline & 3 & $0.4-8.0 \times 10^{7}$ & $0.146(0.022-0.270)$ & $1.1-1.6 \times 10^{7}$ & $0.106(0.051-0.162)$ \\
\hline & 4 & $1.5 \times 10^{6}$ & 0.267 & $1 \cdot 1-2.3 \times 10^{6}$ & $0.133(0.085-0.182)$ \\
\hline
\end{tabular}

Table 2. Production of tissue-destructive protease by L. pneumophila multiplying within human alveolar macrophages

Results of five independent experiments are presented. Viable counts and protease concentration were determined in duplicate. ND, Not detected (the limit of detection of the ELISA was $5 \mathrm{ng}$ of protease); NT, not tested.

\begin{tabular}{|c|c|c|c|c|c|}
\hline \multirow[b]{2}{*}{$\begin{array}{l}\text { Time } \\
\text { (h) }\end{array}$} & \multirow[b]{2}{*}{ Expt } & \multicolumn{2}{|c|}{ Supernatant } & \multicolumn{2}{|c|}{ Lysate } \\
\hline & & $\begin{array}{l}\text { Viable count } \\
\text { (c.f.u. per well) }\end{array}$ & $\begin{array}{l}\text { Concn of protease } \\
\text { ( } \mu \text { g per } 10^{6} \text { bacteria) }\end{array}$ & $\begin{array}{l}\text { Viable count } \\
\text { (c.f.u. per well) }\end{array}$ & $\begin{array}{l}\text { Concn of protease } \\
\text { ( } \mathrm{g} \text { per } 10^{6} \text { bacteria) }\end{array}$ \\
\hline \multirow[t]{5}{*}{0} & 1 & $3.5-8.5 \times 10^{2}$ & ND & $0.6-0.7 \times 10^{4}$ & ND \\
\hline & 2 & $3.0-4.5 \times 10^{2}$ & ND & $0.3-1.0 \times 10^{4}$ & ND \\
\hline & 3 & $5-10 \times 10^{2}$ & ND & $0.8-1.0 \times 10^{4}$ & ND \\
\hline & 4 & $5-8 \times 10^{2}$ & ND & $1.9-2.5 \times 10^{4}$ & ND \\
\hline & 5 & $10-12 \times 10^{2}$ & ND & $1 \cdot 1-1.2 \times 10^{4}$ & ND \\
\hline \multirow[t]{5}{*}{24} & 1 & $4.6-6.8 \times 10^{6}$ & 0.029 & $3 \cdot 1-5 \cdot 5 \times 10^{5}$ & 0.064 \\
\hline & 2 & $3.8-11 \cdot 2 \times 10^{6}$ & 0.029 & $2.4-3.7 \times 10^{5}$ & 0.088 \\
\hline & 3 & $0.8-11 \cdot 1 \times 10^{6}$ & $0.109(0.088-0.125)$ & NT & NT \\
\hline & 4 & $3.4-6.1 \times 10^{6}$ & $0.105(0.095-0.125)$ & $1 \cdot 7-2 \cdot 2 \times 10^{6}$ & $0.104(0.086-0 \cdot 141)$ \\
\hline & 5 & $3.0-4.6 \times 10^{6}$ & $0 \cdot 180(0 \cdot 176-0 \cdot 188)$ & $1.2-1.4 \times 10^{6}$ & $0.066(0.040-0.086)$ \\
\hline
\end{tabular}

\section{Results and Discussion}

In this study, we have shown that a highly virulent clinical isolate of $L$. pneumophila produces tissuedestructive protease intracellularly in similar quantities in guinea-pig and human alveolar macrophages infected in vitro. Within $24 \mathrm{~h}$ of infection, bacterial counts increased by $2-3$ orders of magnitude in both guinea-pig and human alveolar macrophages (Tables 1 and 2). Approximately $0 \cdot 1-0 \cdot 2 \mu \mathrm{g}$ protease per $10^{6}$ L. pneumophila organisms was measured in culture supernatants and cell lysates at $24 \mathrm{~h}$. Protease was not detected immediately after infection, in uninfected cells, or in bacterial suspensions incubated in the absence of cells. Tissue culture media and digitonin had no effect on the ELISA assay.

Since the majority of extracellular bacteria were removed following infection of the cells and bacteria were unable to grow in tissue culture medium alone, bacterial multiplication and protease production must have occurred intracellularly. Large quantities of protease were detected in culture supernatants as a result of 

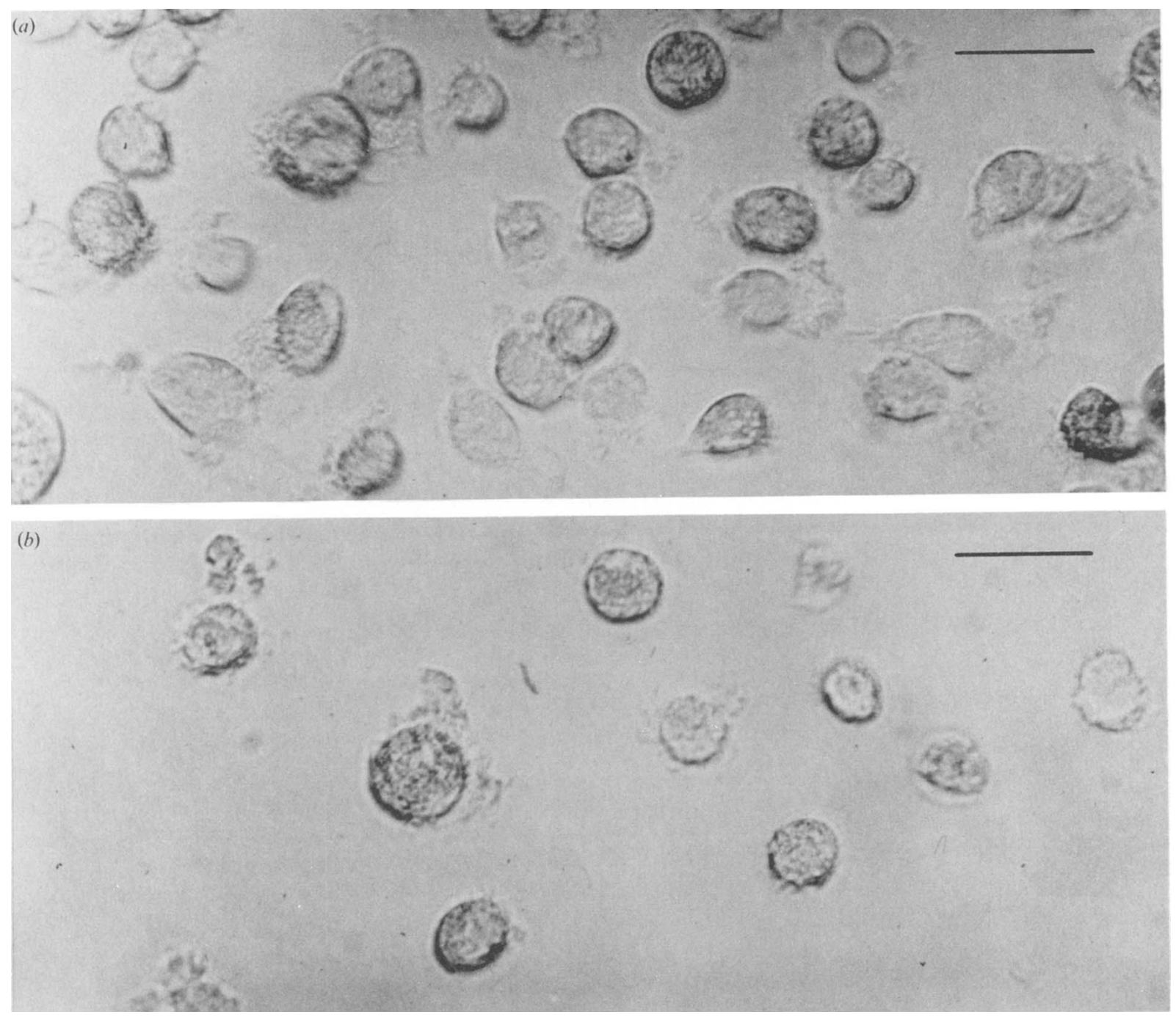

Fig. 1. Phase-contrast micrographs of human alveolar macrophage monolayers: $(a)$ uninfected; $(b)$ after $24 \mathrm{~h}$ infection with L. pneumophila. Bars, $50 \mu \mathrm{m}$.

lysis of the infected macrophages, which was evident on examination of the cells by phase-contrast microscopy (Fig. 1 $a, b$ ). Immunogold labelling of infected guinea-pig alveolar macrophages using anti-protease antibody is shown in Fig. 2(a,b). Specific labelling for protease showed the enzyme to be located within phagosomes and distributed throughout the macrophages. No gold particles were seen on cells incubated with rabbit $\mathrm{IgG}$ in place of anti-protease antibody (Fig. $2 c$ ).

The concentrations of protease quoted in this paper were calculated from comparisons with purified, enzymically active Corby strain tissue-destructive protease used as a standard in the ELISA. Since it is an immunoassay, these figures are not necessarily related to the functional activity of intracellular protease. It would be difficult to estimate protease activity in these samples owing to the presence of endogenous macrophage proteolytic en- zymes. However, since the $L$. pneumophila tissuedestructive protease has previously been shown to be responsible for the severe tissue damage seen in vivo (Baskerville et al., 1986; Conlan et al., 1988; Williams et al., 1987), it is probable that the protease is produced and released from macrophages in a highly active form. Further studies are required to demonstrate and define the functional enzyme activities of this and other proteases produced by Legionella bacteria in the in vitro assay and those produced in vivo in experimentally infected guinea-pigs.

The question of whether the quantities of tissuedestructive protease produced in these in vitro experiments can be related to those found in vivo should be addressed since this has relevance to the role of protease produced during Legionnaires' disease. Numbers of intra- and extracellular bacteria found in the present in 

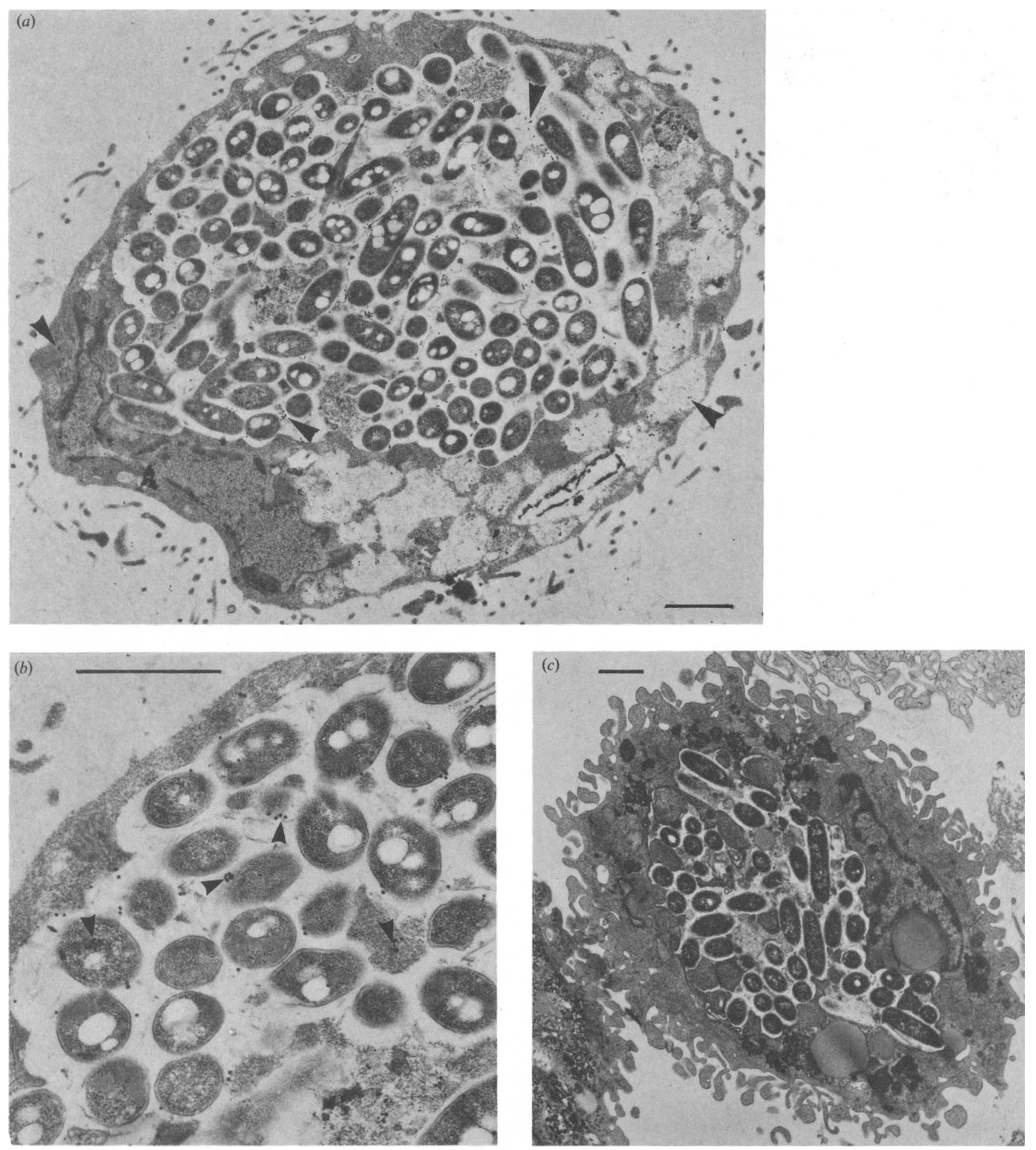

Fig. 2. Immunogold labelling for tissue-destructive protease in sections of guinea-pig alveolar macrophages infected in vitro with $L$. pneumophila. $(a, b)$ Sections of cells incubated with anti-protease antibody showing numerous gold particles $(>)$ both within phagosomes and distributed throughout the cell; $(c)$ section of cells incubated with rabbit IgG in place of anti-protease antibody showing no gold particles. Bars, $1 \mu \mathrm{m}$.

vitro experiments were 10-100-fold lower than those enumerated in vivo following aerosol infection of guineapigs with this strain (Conlan et al., 1988). Assuming that the rate of protease production would remain relatively constant, then a further $10-100$ fold multiplication of the Legionella would result in quantities of protease of the same order, if not greater, than those shown to be inhibitory to phagocytes by Rechnitzer \& Kharazmi 
(1992). These projected levels of protease also equate to those detected in vivo in lung macerates.

The location of protease in vivo should also be considered. The macrophage is well-established as the site of replication of L. pneumophila in vivo. A. Williams \& R. B. Fitzgeorge (unpublished data) have shown that the strain used in this study was unable to grow in cellfree guinea-pig lung lavage, even when this was obtained from animals with experimental Legionnaires' disease. Since this strain is also killed by polymorphonuclear neutrophil leukocytes (Fitzgeorge et al., 1988; Jepras et al., 1985), it would suggest that the macrophage is the principal site of protease production in vivo. Immunocytochemical studies support this suggestion, since the protease was seen concentrated at the sites of lung lesions and only in association with specifically labelled $L$. pneumophila (Williams et al., 1987). Up to $22 \mu \mathrm{g}$ of protease were detected by the same ELISA in total guinea-pig lung macerate by Conlan et al. (1988). Assuming the macrophages to be the major site of protease production, high concentrations of the enzyme would be reached in their vicinity.

A number of previous studies concerning L. pneumophila metalloprotease have suggested an important role of the enzyme in the pathogenesis of Legionnaires' disease. More recently, Szeto \& Shuman (1990) described a transposon mutant of $L$. pneumophila Philadelphia 1 strain which was deficient in protease (major secretory protein, MSP) production. When tested in an aerosol infection guinea-pig model, the mutant was as lethal as its parent strain (Blander et al., 1990). It was thus concluded that the MSP is not a virulence factor of $L$. pneumophila.

In general, virulence may be regarded as being multifactorial and, whilst the protease may not be a major virulence factor, its tissue-destructive properties and recent observations that the enzyme could modify the host inflammatory response (Rechnitzer et al., $1989 b$; Diamant et al., 1991; Rechnitzer \& Kharazmi, 1992) suggest that the protease should not be excluded from having a role in the pathogenesis of Legionnaires' disease.

We wish to thank Dr A. Baskerville and Dr L. A. E. Ashworth for helpful advice and discussion. The skilled assistance of Mr M. S. Lever and Mrs E. Elphick is gratefully acknowledged. The study was supported by the Weimann Foundation, the Lundbeck Foundation, and the Foundation for the Advancement of Medical Science (C.R.).

\section{References}

Baskerville, A., Conlan, J. W., Ashworth, L. A. E. \& Dowsett, A. B. (1986). Pulmonary damage caused by a protease from Legionella pneumophila. British Journal of Experimental Pathology 67, $527-536$.
Belyi, I. F., Vertiev, I. V., Tartakovski, I. S., EzePchuck I. V. \& ProsorovsKII, S. V. (1988). Characteristics of the cytolysin of Legionella pneumophila. Zhurnal Mikrobiologii, Epidemiologii i Immunobiologii 2, 4-7.

BLANDER, S. J. \& HoRwitz, M. A. (1989). Vaccination with the major secretory protein of Legionella pneumophila induces cell-mediated and protective immunity in a guinea pig model of Legionnaires' disease. Journal of Experimental Medicine 169, 691-705.

Blander, S. J., Szeto, L., Shuman, H. A. \& Horwitz, M. A. (1990). An immunoprotective molecule, the major secretory protein of Legionella pneumophila, is not a virulence factor in a guinea pig model of Legionnaires' disease. Journal of Clinical Investigation 86, 817-824.

Conlan, J. W., Baskerville, A. \& Ashworth, L. A. E. (1986). Separation of Legionella pneumophila proteases and purification of a protease which produces lesions like those of Legionnaires' disease in guinea pig lung. Journal of General Microbiology 132, 1565-1574.

Conlan, J. W., Williams, A. \& Ashworth, L. A. E. (1988). In vivo production of a tissue-destructive protease by Legionella pneumophila in the lungs of experimentally infected guinea pigs. Journal of General Microbiology 134, 143-149.

Diamant, M., Rechnitzer, C., Christensen, L. D. \& Pedersen, B. K. (1991). Cleavage of the CD4 molecular complex by Legionella pneumophila protease. Immunology and Infectious Diseases 1, 167-171.

Dreyfus, L. A. \& IglewSKI, B. H. (1986). Purification and characterization of an extracellular protease of Legionella pneumophila. Infection and Immunity 51, 736-743.

ElliotT, J. A. \& WINN, W. C., JR (1986). Treatment of alveolar macrophages with cytochalasin D inhibits uptake and subsequent growth of Legionella pneumophila. Infection and Immunity 51, 31-36.

FITZGEORGE, R. B. (1985). The effect of antibiotics on the growth of Legionella pneumophila in guinea pig alveolar phagocytes infected in vivo by an aerosol. Journal of Infection 10, 189-193.

Fitzgeorge, R. B., Featherstone, A. S. R. \& Basker Ville, A. (1988). Effects of polymorphonuclear leucocyte depletion on experimental Legionnaires' disease. British Journal of Experimental Pathology 69, 105-112.

Horwitz, M. A. \& Silverstein, S. C. (1980). Legionnaires' disease bacterium (Legionella pneumophila) multiplies intracellularly in human monocytes. Journal of Clinical Investigation 66, 441-450.

Jepras, R. I., Fitzgeorge, R. B. \& Baskerville, A. (1985). A comparison of virulence of two strains of Legionella pneumophila based on experimental aerosol infection of guinea pigs. Journal of Hygiene 95, 29-38.

Kishimoto, R. A., White, J. D., Shirey, F. G., McGanN, V. G., BERENDT, R. F., LARSON, E. W. \& HedLUND, K. W. (1981). In vitro response of guinea pig peritoneal macrophages to Legionella pneumophila. Infection and Immunity 31, 1209-1213.

Mintz, C. S., Chen, J. \& Shuman, H. A. (1988). Isolation and characterization of auxotrophic mutants of Legionella pneumophila that fail to multiply in human monocytes. Infection and Immunity 56, 1449-1455.

NASH, T. W., LibBy, D. M. \& HoRwitz, M. A. (1984). Interaction between the Legionnaires' disease bacterium (Legionella pneumophila) and human alveolar macrophages. Influence of antibody, lymphokines, and hydrocortisone. Journal of Clinical Investigation 74, 771-782.

Rajagopalan, P., Dournon, E., Vilde, J.-L. \& Pocidalo, J.-J. (1987). Direct activation of human monocyte-derived macrophages by a bacterial glycoprotein extract inhibits the intracellular multiplication of virulent Legionella pneumophila serogroup 1. Infection and Immunity 55, 2234-2239.

RECHNITZER, C. \& KHARAZMI, A. (1992). Effect of Legionella pneumophila cytotoxic protease on human neutrophil and monocyte function. Microbial Pathogenesis 12, 115-125.

Rechnitzer, C., Tvede, M. \& DöRING, G. (1989a). A rapid method for purification of homogeneous Legionella pneumophila protease using fast protein liquid chromatography. FEMS Microbiology Letters 59, 39-44.

Rechnitzer, C., Diamant, M. \& Pedersen, B. K. (1989b). Inhibition of human natural killer cell activity by Legionella pneumophila protease. European Journal of Clinical Microbiology and Infectious Diseases 8, 989-992. 
Rosenfeld, J. S., Kueppers, F., NewkiRk, T., TaMada, R., Meissler, J. J., JR \& EISENSTEIN, T. K. (1986). A protease from Legionella pneumophila with cytotoxic and dermal ulcerative activity. FEMS Microbiology Letters 37, 51-58.

Szeto, L. \& Shuman, H. A. (1990). The Legionella pneumophila major secretory protein, a protease, is not required for intracellular growth or cell killing. Infection and Immunity 58, 2585-2592.

Williams, A., Baskerville, A., Dowsett, A. B. \& Conlan, J. W. (1987). Immunocytochemical demonstration of the association between Legionella pneumophila, its tissue-destructive protease, and pulmonary lesions in experimental Legionnaires' disease. Journal of Pathology 153, 257-264.

Yamamoto, Y., Klein, T. W., Newton, C. A., Widen, R. \& FRIEDMAN, H. (1987). Differential growth of Legionella pneumophila in guinea pig versus mouse macrophage culture. Infection and Immunity 55, 1369-1374.

Yoshida, S., Mizuguchi, Y., Nikaido, Y., Mitsuyama, M. \& Nomoтo, K. (1987). Fate of Legionella pneumophila, Philadelphia-1 strain in resident, elicited, activated and immune peritoneal macrophages of guinea pigs. Infection and Immunity 55, 2477-2482. 